\title{
Partial Gastric Resection for Symptomatic Anemia following Diagnosis of Merkel Cell Carcinoma (MCC) of the Skin with Gastric Metastasis
}

Zachary Eagle ${ }^{1}$, Francis Essien ${ }^{2}$, George Shahin ${ }^{2}$, Amia Jones ${ }^{3}$, John McKee ${ }^{3}$, and Wassem Juakiem ${ }^{2}$

${ }^{1}$ Keesler AFB 81st MDG

${ }^{2}$ Keesler Air Force Base

${ }^{3}$ Singing River Health System

June 26, 2021

\begin{abstract}
Merkel Cell Carcinoma (MCC) is a rare dermatologic malignancy with propensity for metastasis to lymph nodes, skin, lung, liver, bone, and brain. Metastasis to the stomach is rare with only 13 reported cases. We discuss the outcomes of a partial gastrectomy for the treatment of symptomatic MCC with gastric metastasis.
\end{abstract}

Title: Partial Gastric Resection for Symptomatic Anemia following Diagnosis of Merkel Cell Carcinoma (MCC) of the Skin with Gastric Metastasis

Authors: Zachary Eagle, $\mathrm{MD}^{1}$; Francis Essien, $\mathrm{DO}^{1}$; George Shahin, $\mathrm{MD}^{2}$; Amia Jones, $\mathrm{MD}^{3}$; John McKee, MD $^{3}$; Wassem Juakiem, MD $^{4}$

Author Affiliations:

${ }^{1}$ Keesler Air Force Base, MS; Keesler Medical Center, Department of Internal Medicine

${ }^{2}$ Keesler Air Force Base, MS; Keesler Medical Center, Department of Internal Medicine, Division of Hematology and Oncology

${ }^{3}$ Singing River Hospital System; Department of Internal Medicine, Division of Gastroenterology

${ }^{4}$ Keesler Air Force Base, MS; Keesler Medical Center, Department of Internal Medicine, Division of Gastroenterology

Corresponding Author: Zachary Eagle

Zachary Eagle

Keesler Medical Center

301 Fisher Street

Keesler AFB 39534 Email:zachary.r.eagle2.mil@mail.mil

Abstract: 
Merkel Cell Carcinoma (MCC) is a rare dermatologic malignancy with propensity for metastasis to lymph nodes, skin, lung, liver, bone, and brain..$^{1,2}$ Metastasis to the stomach is rare with only 13 reported cases. ${ }^{3-15}$ We discuss the outcomes of a partial gastrectomy for the treatment of symptomatic MCC with gastric metastasis.

\section{Key clinical message:}

Anemia may be a significant cause of the morbidity and mortality associated with MCC with gastric metastasis. Our case demonstrates a positive outcome associated with partial gastric resection and presents a possible treatment option for this rare disease process.

\section{Introduction}

Merkel Cell Carcinoma (MCC) is a rare, highly aggressive cutaneous dermatologic malignancy with an incidence of 0.7 per 100,000 persons that is typically seen in older, fair skinned adults. ${ }^{1}$ Development of MCC is attributed to multiple risk factors such as Merkel Cell Polyomavirus, ultraviolet (UV) radiation, and immunosuppression. ${ }^{1}$ MCC has a high propensity for metastasis with the most common sites being lymph nodes, skin, lung, liver, bone, and brain. ${ }^{1,2}$ Though the malignancy is uncommon, recorded metastasis to the stomach is exceedingly rare with only 13 identified cases reported in the literature. ${ }^{3-15}$ In this case report, we discuss the outcomes of a partial gastrectomy for the treatment of symptomatic MCC with gastric metastasis.

\section{Case Description}

An 84-year-old African American male with recently diagnosed metastatic MCC presented to the emergency room with progressively worsening shortness of breath, fatigue, and melena. A positron emission tomographic (PET) scan at the time of diagnosis showed bulky hyper-metabolic inguinal adenopathy and left hilar lymph node. He had been initiated on immunotherapy treatment with pembrolizumab. Patient denied any recent history of peptic ulcer disease, anticoagulation therapy, or recent non-steroidal anti-inflammatory drug (NSAID) use. On physical exam, the abdomen was non-tender without guarding or rigidity, however rectal exam showed maroon colored stools. Laboratory analysis was notable for a hemoglobin of $4.8 \mathrm{~g} / \mathrm{dL}$. Aggressive intravenous fluid resuscitation, red blood cell transfusions and proton pump inhibitor therapy was immediately initiated. Gastroenterology was consulted and performed an upper endoscopy which revealed a malignant appearing 3-cm ulcerated gastric nodule with stigmata of recent bleeding (Figure 1). Gastric biopsy results showed focally ulcerated MCC. A partial gastrectomy was performed during hospitalization with resolution of the patient's bleeding. One year after resection, our patient remains asymptomatic with stable hemoglobin.

\section{Discussion}

Though rare, the incidence of MCC has tripled over the last decade and mortality from advanced MCC has risen by over 300 percent. ${ }^{16,17}$ The exact reason for the increasing incidence and mortality is not well understood at this time but may be due to improved understanding of the pathogenesis, aging populations, increased immunocompromised patients, and refined diagnostic tools. ${ }^{15}$

The diagnosis of MCC begins with high clinical suspicion. The AEIOU acronym was developed by Heath et $a l$. and summarized the common clinical findings: asymptomatic, expanding rapidly, immunosuppressed, older age, and UV exposure. ${ }^{18}$ The gold standard for diagnosis is biopsy as MCC must be differentiated from other neuroendocrine tumors such as melanoma, cutaneous lymphoma, and small cell lung carcinoma. ${ }^{19}$ Immunohistochemical analysis is crucial to detect the presence of CK-20, which is a highly sensitive marker for MCC. ${ }^{19}$ The absence of TTF-1, S-100, and leukocyte-common antigen, markers recognized in other neuroendocrine tumors, allows to further refine the accuracy of the diagnosis.$^{19,20}$

According to the National Comprehensive Cancer Network, immunotherapy with PD-1/PD-L1 blockade is typically used for metastatic MCC due to improved side effect profile when compared with chemotherapy or surgery. ${ }^{21,22}$ Given the rarity of metastasis of MCC to the gastric mucosa, no clear treatment guidelines have been established. Gastrointestinal bleeding appears to be the most common presentation of MCC with 
gastric metastasis. ${ }^{3-15}$ Mortality rates range from 1 week to 24 months with an average mortality rate of $67 \%$ at 4 months following diagnosis of gastric metastasis. ${ }^{3-15}$ Of the 13 case reports identified, two patients underwent aggressive surgical intervention in addition to traditional pharmacologic regimens. One prior study reports the use of a Billroth II resection with subsequent survival at 24 month follow-up. ${ }^{15}$ Another study describes a patient that underwent an emergent wedge resection following gastric perforation and continued survival at 18 months. ${ }^{3}$ Partial gastric resection was pursued in our patient as he was already on immunotherapy and was high risk for re-current symptomatic anemia. Over 12 months after resection, the patient's had no recurrent bleeding events with a stable hemoglobin of $13.9 \mathrm{~g} / \mathrm{dl}$.

Anemia may play an important part in the role of the morbidity and mortality associated with MCC with gastric metastasis. Our patient demonstrated hematologic stability and symptomatic improvement following partial gastric resection. However, given the rarity and early mortality associated with this presentation, further research into the efficacy of partial gastric resection may prove difficult. Our case report demonstrates a positive outcome associated with partial gastric resection and presents a possible treatment option for this rare disease process.

Authors: Zachary Eagle, $\mathrm{MD}^{1}$; Francis Essien, $\mathrm{DO}^{1}$; George Shahin, $\mathrm{MD}^{2}$; Amia Jones, $\mathrm{MD}^{3}$; John McKee, $\mathrm{MD}^{3}$; Wassem Juakiem, $\mathrm{MD}^{4}$

The authors confirm contribution to the paper as follows:

Study conception and design: Zachary R Eagle MD $^{\mathbf{1}}$; Francis Essien $\mathbf{D O}^{\mathbf{1}}$; Wassem Juakiem, MD $^{4}$ Data collection Zachary R Eagle MD ${ }^{1}$; Amia Jones, MD ${ }^{3}$; John McKee, MD ${ }^{3}$; Wassem Juakiem, $\mathrm{MD}^{4}$

Analysis and interpretation of results: Zachary R Eagle $\mathbf{M D}^{\mathbf{1}}$; Wassem Juakiem, MD4

Draft manuscript preparation: Zachary R Eagle MD $^{\mathbf{1}}$; Francis Essien DO ${ }^{\mathbf{1}}$; George Shahin, MD2; Wassem Juakiem, $\mathrm{MD}^{4}$

All authors discussed the results and contributed to the final manuscript.

Data sharing is not applicable to this article as no new data were created or analyzed in this study.

\section{References:}

1. Agelli M, Clegg LX. Epidemiology of primary Merkel cell carcinoma in the United States [published correction appears in J Am Acad Dermatol. 2004 May;50(5):733]. J Am Acad Dermatol . 2003;49(5):832841. doi:10.1016/s0190-9622(03)02108-x

2. Albores-Saavedra J, Batich K, Chable-Montero F, et al. Merkel cell carcinoma demographics, morphology, and survival based on 3870 cases: a population based study. J Cutan Pathol 2010;37:20-7

3. Trivedi, D; Collins, V; Roberts, E; et al. Perforated gastric metastasis of Merkel cell carcinoma: Case report and review of the literature. Human Pathology. Jan 2017, Vol 8;20-23

4. P.M. Parikh, S. Samo, V. Ganipisetti, et al. Gastric metastasis of Merkel cell carcinoma, a rare cause of gastrointestinal bleeding: Case report and review of the literature J. Gastrointest. Oncol ., 5 (4) (2014), pp. E68-E72

5. Syal NG, Dang S, Rose J, et al. Gastric metastasis of merkel cell cancer-uncommon complication of a rare neoplasm. J Ark Med Soc 2012;109:134-6

6. Idowu M, Contos M, Gill S, et al. Merkel cell carcinoma: A report of gastrointestinal metastasis and review of the literature. Arch. Pathol. Lab. Med ., 127 (2003), pp. 367-369

7. Hu Z, Schuster J, Kudelka A, et al., Merkel cell carcinoma with gastric metastasis and review of literature. J Cutan. Med. Surg ., 20 (3) (2016), pp. 255-258

8. Maria A, Limin C, Epidemiology of primary Merkel cell carcinoma in the United States. J. Am. Acad. Dermatol. , 49 (5) (2003), pp. 832-841

9. Tarantola T, Vallow L, Halyard M, et al. Prognostic factors in Merkel cell carcinoma: Analysis of 240 cases. J. Am. Acad. Dermatol ., 68 (2013), pp. 425-432 
10. Li M, Liu C., Cytokeratin 20 confirms Merkel cell metastatis to stomach. Appl. Immunohistochem . Mol. Morphol ., 12 (4) (2004), pp. 346-349

11. Canales LI, Parker A, Kadakia S. Upper gastrointestinal bleeding from Merkel cell carcinoma. Am J Gastroenterol . 1992;87(10):1464-6

12. Krasagakis K, Almond-Roesler B, Zouboulis CC, et al. Merkel cell carcinoma: report of ten cases with emphasis on clinical course, treatment, and in vitro drug sensitivity. J Am Acad Dermatol . 1997;36(5 Pt 1):727-32

13. Cubiella J, Salgado M, Riu M, Garcia-Mata J, Sanchez E, Diez MS, et al. Gastric metastatis due to Merkel cell carcinoma: a rare cause of gastric bleeding. Rev Esp Enferm Dig . 2004;96(2):150-1

14. Wolov K, Tully O, Mercogliano G. Gastric metastasis of Merkel cell carcinoma. Clin Gastroenterol Hepatol . 2009;7(3):A26.

15. Rosa F, Pacelli F, Papa V, et al. Merkel cell carcinoma metastatic to the stomach. ANZ J Surg . 2010;80(1-2):100-1.

16. Schadendorf D, Lebbé C, Zur Hausen A, Avril MF, Hariharan S, Bharmal M, Becker JC. Merkel cell carcinoma: Epidemiology, prognosis, therapy and unmet medical needs. Eur J Cancer. 2017 Jan;71:5369. doi: 10.1016/j.ejca.2016.10.022. Epub 2016 Dec 14. PMID: 27984768.

17. Fitzgerald T.L., Dennis S., Kachare S.D., Vohra N.A., Wong J.H., Zervos E.E. Dramatic increase in the incidence and mortality from Merkel cell carcinoma in the United States. Am Surg . 2015 Aug; 81: 802-806

18. Heath M, Jaimes N, Lemos B, Mostaghimi A, Wang LC, Peñas PF, Nghiem P. Clinical characteristics of Merkel cell carcinoma at diagnosis in 195 patients: the AEIOU features. J Am Acad Dermatol. 2008 Mar;58(3):375-81. doi: 10.1016/j.jaad.2007.11.020. PMID: 18280333; PMCID: PMC2335370.

19. Bichakjian, C.K., Lowe, L., Lao, C.D., Sandler, H.M., Bradford, C.R., Johnson, T.M. and Wong, S.L. (2007), Merkel cell carcinoma: Critical review with guidelines for multidisciplinary management. Cancer, 110: 1-12.https://doi.org/10.1002/cncr.22765

20. Bobos M,Hytiroglou P,Kostopoulos I,Karkavelas G,Papadimitriou CS. Immunohistochemical distinction between Merkel cell carcinoma and small cell carcinoma of the lung. Am J Dermatopathol. 2006; 28: 99- 104.

21. NCCN Guidelines version 1. 2021. Merkel Cell Carcinoma. Available online: http://www.nccn.org/professionals/physician_gls/pdf/mcc.pdf

22. Nghiem P, Bhatia S, Lipson EJ, et. Al. Durable tumor regression and overall survival in patients with advanced merkel cell carcinoma receiving pembrolizumab as first-line therapy. J Clin Oncol2019;37:693702

\section{Hosted file}

Figure.docx available at https://authorea.com/users/422167/articles/527915-partial-gastricresection-for-symptomatic-anemia-following-diagnosis-of-merkel-cell-carcinoma-mcc-ofthe-skin-with-gastric-metastasis 